\title{
REPRESENTAÇÕES E CONSTRUÇÕES DA AN- TIGUIDADE POR MEIO DAS SÉRIES DE TV: O CASO DO SERIADO “ROME”
}

\section{REPRESENTACIONES Y CONSTRUCCIONES DE LA ANTI- GÜEDAD A TRAVÉS DE LAS PRODUCCIONES DE TELEVI- SIÓN: EL CASO DE LA SERIE “ROME”}

Victor Henrique S. Menezes ${ }^{1}$

Resumo: Este trabalho apresentará algumas considerações acerca da forma como a Roma do séc. I a. C foi representada no seriado "Rome" (2005-2007), produzido pelas redes de televisão HBO, BBC e RAI. Para tal, faremos uma aproximação dos campos da História, Cinema e Televisão. Parte-se do pressuposto de que, assim como os estudos historiográficos, as produções cinematográficas e televisivas são narrativas que criam discursos acerca de determinados momentos do passado, e que, mesmo que não seja as intenções dos produtores (que devem ser consideradas), mostrarão o passado a partir de perspectivas do presente. Destarte, serão analisados alguns dos depoimentos de produtores, diretores e consultores de história que atuaram na produção de "Rome" com o intuito de ponderar acerca das influências do presente nos discursos que foram/são emitidos pela série. Como os produtores procuraram representar a cidade de Roma, bem como as suas possíveis influências, são questionamentos norteadores deste ensaio.

\footnotetext{
${ }^{1}$ Graduando em História pela Universidade Estadual de Campinas (Unicamp) e estagiário do Laboratório de Arqueologia Pública Paulo Duarte (LAP/NEPAM/Unicamp). Contato: henrique.menezes92@gmail.com.

Agradeço a Pedro Paulo Funari, meu orientador, pelas críticas e sugestões dirigidas ao texto. Sou igualmente grato aos amigos Thiago Biazotto, Natália Campos, Aline Carvalho, Raquel Funari, Gabriela Morais, Renato Pinto e Camila Secolin pela leitura, crítica e apoio bibliográfico oferecido. E, também, ao apoio institucional da Unicamp e do Laboratório de Arqueologia Pública Paulo Duarte (LAP/NEPAM/Unicamp). As ideias aqui apresentadas são de inteira responsabilidade do autor.
} 
Palavras-chave: Televisão; Cinema; Representações; Roma.

Resumen: Este artículo presentará algunas consideraciones sobre la forma como la antigüedad fue representada en serie "Rome" (20052007), producida por la cadena de televisión HBO, BBC y RAI. Para esto, nos acercaremos a los campos de la Historia, Cine y Televisión. Se asume la suposición de que, como los estudios historiográficos, las producciones cinematográficas y televisivas son narraciones que crean discursos sobre ciertos momentos del pasado, y que, aunque no sea la intención de los productores, muestran el pasado desde perspectivas del presente. Así, se analizarán algunos de los testimonios de los productores, directores y consultores que trabajaron en la historia de la producción de "Rome" con el fin de reflexionar sobre las influencias presentes en los discursos que fueron/son emitidos por la serie. Como los productores representaron a la ciudad de Roma y sus posibles influencias, son algunas de las preguntas que sirven de guía para este ensayo.

Palabras clave: Televisión; Cine; Representaciones; Roma.

\section{Introdução}

Uma grande parte dos estudos historiográficos empreendidos na época atual partem do pressuposto de que é impossível retornar ao passado tal como aconteceu, e que, as construções e representações feitas deste estão influenciadas pelo presente que as concebe. Considera-se que a produção historiográfica depende das condições sociais, políticas, econômicas e culturais nas quais o historiador está inserido (CERTEAU, 2007: 65-66). Este produz em seu ofício, espaços, tempos, indivíduos e práticas, ao passo que ele próprio, como historiador, encontra-se inserido em contextos e conjunturas específicas (SILVA, 2007: 17). Dessa forma, é impossível pensar a História, considerada como um dentre uma série de discursos a respeito do mundo (JENKINS, 2013: 23), sem reflexões acerca dos momentos e sociedades que a produz. Os fatos histó- 
ricos, como apontam Lourdes Feitosa e Glaydson José da Silva (2009: 211), não estão prontos à espera de revelação, dispostos em uma sequência contínua, mas a sua escolha como objeto de estudo, a sua abordagem e interpretação, resultam das opções do historiador.

O passado, ao ser construído, alterado e moldado de acordo com questões e problemáticas do presente torna-se um outro. Um outro distante no tempo, mas que se aproxima, por meio de discursos, do presente para responder dúvidas, anseios, ou mesmo preencher lacunas. $\mathrm{O}$ passado, portanto, esse outro, pode ser (re) utilizado em diversos contextos com diferentes intuitos, uma vez que um mesmo momento e as mesmas personagens podem ser totalmente adaptados a ponto de parecerem distintos entre si (SILVA, 2007: 15). Tais pressupostos estão também inseridos em alguns dos estudos acerca do Mundo Antigo que centros acadêmicos internacionais e brasileiros passaram a desenvolver ao longo das últimas décadas. Como resultado da multiplicação de movimentos sociais a partir da década de 1960 e a consequente negação de modelos normativos (MUNSLOW, 1997), o número de pesquisas que olham para a Antiguidade, não com o intuito de entender como tal evento aconteceu ou personagem viveu, mas sim estudar as interpretações e representações que as sociedades posteriores deles fizeram, aumentou ao longo dos últimos anos.

No Brasil, como apontam os estudiosos Marina Cavicchioli e Pedro Paulo Funari (2011: 112), a expansão desses estudos deu-se no contexto de renovação da historiografia, em geral, e sobre a Antiguidade em particular. Deve-se, em especial, à interação que a disciplina passou a 
ter, de forma mais intensa, com as outras Ciências Humanas e Sociais, “em busca de interpretações que superassem as aporias teóricas e práticas do estudo das sociedades no presente e no passado" (ibidem). Os autores ainda completam que no Brasil, cada vez mais atento à sua inserção nas discussões internacionais, estudos acerca dos usos do passado "passaram a ocupar lugar de destaque" (idem). A pesquisa no âmbito dos usos do passado, por sua vez, como explica o pesquisador Renato Pinto (2011: 30), não se refere a um estudo no qual se pretenda que alguém na modernidade vá ao passado e o traga como foi ao seu mundo contemporâneo, mas busca a compreensão de como os conceitos e ideologias do passado são interpretados e representados no presente. Entende-se que esse pressuposto teórico e metodológico não tem como foco apenas os discursos historiográficos produzidos dentro da academia, mas também se preocupa com os discursos e as representações do passado que estão presentes em outras narrativas históricas. Essas narrativas que divulgam múltiplas concepções - ligadas ao momento em que são elaboradas - de acontecimentos e personagens do passado, também estão presentes, por exemplo, em produções cinematográficas e televisivas. Tais narrativas, assim como os estudos de História e Arqueologia voltados para o mundo clássico, são discursos sobre o passado e, portanto, "formadores de noções de identidade e maneiras de ver o mundo no passado e presente" (GARRAFFONI, 2013: 224).

Com tais conjecturas, a atenção para a relação entre passadopresente tem sido prática corrente entre os pesquisadores interessados na análise de filmes e seriados de TV sobre momentos e personagens histó- 
ricos (FEITOSA \& VICENTE, 2012: 178), que, de longe, são as narrativas com as quais a população, em geral, tem um maior contato. Assim como qualquer outro produto preocupado em apresentar narrativas sobre o passado, as produções cinematográficas e televisivas ligam-se às convicções políticas, religiosas, de gênero e aos valores e normas sociais do período e da sociedade que os produziram (FUNARI, 2012: 31). Não é incomum encontrarmos no cinema discursos que tornam modelos de comportamento ou mesmo objetos como naturais; como se eles tivessem uma existência anterior até ao próprio homem. A colocação destes discursos no tempo/espaço da Antiguidade potencializa o efeito narrativo da "antiguidade" do comportamento/objetos. É bastante claro, todavia, que esses discursos mudam de acordo com os contextos históricos em que são produzidos. Não à toa, por exemplo, temos os heróis dos filmes sobre a Antiguidade produzidos em especial entre os anos 1930 e anos 1960 como homens mais velhos e com características como a dureza. Enquanto que alguns dos heróis dos anos 2000 são adolescentes em busca de aventuras (como o protagonista da série Percy Jackson).

Ao pensar-se na representação da Antiguidade em filmes e seriados, procura-se analisar justamente a produção desses discursos. Que imagens estão sendo construídas para um passado que estaria supostamente distante temporalmente do presente? Que usos são imbuídos e permitidos para essas construções? Como pode-se pensar essas relações passado/presente e, principalmente, quais os efeitos discursivos desses entrelaços temporais? Seguindo tais perspectivas, no caso específico deste ensaio, focar-se-á na construção de imagens acerca da cidade de 
Roma e suas relações com as ideias de civilização, ocidente e oriente. Para tal, foi tomado como estudo de caso o seriado "Rome” (20052007), considerado como uma das produções mais caras e de maior repercussão da história televisiva.

\section{Cinema, Televisão e História}

No momento atual, é notória a forma como os ambientes midiáticos estão inseridos no cotidiano das pessoas, onde "o modo de ser e de pensar é perpassado pela imagem, pelo imaginário, pelo simbólico, pelo virtual" (FEITOSA \& VICENTE, 2012: 178). Com isso, o cinema e a televisão cumprem um importante papel na representação daquilo que já não existe mais; que, por meio de uma tela, torna-se presente, e por sua vez, reconstrói uma memória do outro distante, que é o passado. Instrumentos cruciais para a formação e divulgação de uma ampla percepção sobre diferentes momentos históricos (WYKE, 1997), os filmes e seriados televisivos também constroem narrativas sobre o passado influenciadas por questões do presente que acabam por ser consideradas por seus telespectadores, quase sempre, como reais, como representações $d a$ verdade daquilo que aconteceu. Por sua vez, a linguagem cinematográfica, escreve Raquel Funari (2012: 30), “está ao alcance de todos e prescinde de uma educação formal dos sentidos, à diferença da escrita, dependente de um domínio de códigos e estruturas gramaticais e linguísticas padronizadas".

Como disserta Robert Rosenstone (2010: 17), "primeiro o cinema e, mais tarde, o seu rebento eletrônico, a televisão, se tornaram em al- 
gum momento do século XX, o principal meio para transmitir as histórias que nossa cultura conta para si". Ainda que, em muitos aspectos, os filmes e séries de TV continuem sendo vistos como um entretenimento (CHEVITARESE, 2013: 21), são também documentos do presente e, como argumenta o historiador Marc Ferro (1992), precisam ser analisados pelo rigor da pesquisa histórica (FEITOSA \& VICENTE, 2012; CHEVITARESE, 2013). As narrativas cinematográficas e televisivas, que tratam de temas históricos, desenvolvem um papel semelhante ao do historiador em construir memórias e interpretações dos acontecimentos passados, e assim como as narrativas historiográficas, se "expressa de acordo com a visão de quem o produz" (FAZIO, 2009: 293). Por conseguinte, é inegável, nos dias atuais, como aponta Rosenstone (2010: 17), a importância desse tipo de documentação para pesquisas que pretendem refletir os diferentes significados que o passado tem para o presente:

(...) Filmes, minisséries, documentários e docudramas históricos de grande bilheteria são gêneros cada vez mais importantes em nossa relação com o passado e para o nosso entendimento da história. Deixá-los fora da equação quando pensamos o sentido do passado significa nos condenar a ignorar a maneira como um segmento enorme da população passou a entender os acontecimentos e as pessoas que constituem a história (ibidem).

Em uma linha de pensamento semelhante, José D’Assunção Barros (2012: 75) lembra que qualquer filme, "seja policial, de ficção científica, uma pornochanchada, ou um filme de amor, pode ser constituído em fonte pelo historiador interessado em compreender a sociedade que o 
produziu e que o tornou possível como obra". Visto que os filmes e seriados históricos, mesmo quando sabemos que são representações fantasiosas ou ideológicas, afetam a maneira como vemos o passado (ROSENSTONE, 2010: 18), torna-se importante então buscar evidências que permitam perceber e compreender como determinados eventos e períodos históricos adquirem sentido nesse tipo de narrativa (FEITOSA; VICENTE, 2012: 179). Pois, na análise de produções televisivas e cinematográficas históricas $^{2}$, como disserta Marcos Napolitano (2008: 75), o importante não é focar o estudo apenas no que se encena do passado, mas em como se encena, e também, no que não se encena.

Entende-se que um filme, seriado ou documentário não ilustra nem reproduz a realidade, mas a reconstrói a partir de uma linguagem própria produzida num determinado momento histórico (FEITOSA; VICENTE, 2012: 181). Esse tipo de narrativa, como qualquer outra, representa os contextos discursivos de sua época de produção, e por tentar reconstruir um passado distante de forma que crie identificações com o presente, pode ser considerada como um "lugar especial da memória" (KORNIS, 2008: 14). A História construída por esses veículos, com recursos narrativos diversos dos discursos acadêmicos, mas que como tal cria e reconstrói memórias, interpretações e versões de personagens e eventos do passado, possui um grande poder de atração para o

2 Por produções televisivas e cinematográficas históricas, utilizando-se da conceituação de Robert Rosenstone (2010: 15), entendemos como obras que tentam conscientemente recriar o passado. 
telespectador, que esperará encontrar verossimilhanças entre essa representação e um passado tal como teria acontecido.

Os filmes e as produções televisivas podem ser compreendidos como agentes da história e não somente um produto, e podem servir como doutrinação e até mesmo glorificação (KORNIS, 2008: 29), como atestam filmes criados com o intuito de propaganda política do regime nazista, tendo como maior exemplo, os filmes "O triunfo da vontade" (1935) e "Olímpia" (1938), da cineasta Leni Riefenstahl. As narrativas fílmicas e televisivas possuem uma eficácia como instrumento formador de consciência (NÓVOA, 2012: 43) e, em geral, emitem uma mensagem favorável às correntes de pensamentos dominantes (ESPAÑA, 2013: 45). Tais pressupostos levam alguns historiadores, como Jorge Nóvoa (2012: 46) a afirmarem que essas narrativas tornaram-se "um insubstituível instrumento de produção e difusão não de consciência real, muito menos de ciência, mas de massificação de ideologia mantedora do status $q u o$ ". Porém, se tais narrativas podem ser examinadas como "instrumento de dominação e de imposição hegemônica, também podem ser examinadas como meio de resistência" (BARROS, 2012: 64). Para além do caráter de uso político e imposição de ideias dominantes, filmes e séries de TV são também registros das representações e das visões de mundo presentes nas sociedades que os produziram (BARROS, 2012: 66), bem como daquelas para as quais foram produzidos. Ainda, como destaca Raquel Funari (2012: 32), o cinema e a televisão, antes que "receptores", formam 
(...) sujeitos dotados de valores e saberes, em interação, de forma ativa, na produção de significado das mensagens. Os espectadores não são, para parafrasear Paulo Freire, um banco, que recebe, de forma passiva, os valores da mídia. Suas experiências, valores, referências e interesses interpretam e interagem os filmes. $\mathrm{O}$ espectador não vê o que o diretor quer que ele veja, mas recompõe as imagens ao seu modo.

O interesse pelos estudos de representações, construções e apropriações do passado, em especial do período conhecido como Antiguidade, por meio de narrativas midiáticas, apesar de polêmico, tem aumentado ao longo dos últimos anos. Enquanto estão inseridos, a título de exemplo, no campo da classical reception studies no mundo anglosaxão, ou, no estudo das tradições clássicas em países hispânicos (ANTELLA-BERNÁRDEZ \& MARTÍN, 2013: 11-12), no Brasil, as pesquisas dedicadas às relações entre antiguidade e modernidade por meio de filmes e séries de TV dialogam, em especial, com os trabalhos desenvolvidos no âmbito dos usos e representações do passado ${ }^{3}$. Como afirmam Borja Antela-Bernárdez e César Sierra Martín (2013: 11), “a

${ }^{3}$ Como exemplo de estudos preocupados com a relação entre Cinema e História Antiga desenvolvidos no Brasil, podemos citar, entre outros, as recentes obras O príncipe do Egito: um filme e suas leituras na sala de aula de Raquel dos Santos Funari, e, Jesus no cinema: um balanço histórico e cinematográfico entre 1905-1927, do historiador da Universidade Federal do Rio de Janeiro (UFRJ), André Leonardo Chevitarese. Enquanto a obra de Raquel Funari tem por intuito o estudo da relação entre Cinema, História e Ensino de História, utilizando como documento o filme "O Príncipe do Egito" (1998) dos fundadores da Dreamworks Pictures, David Geffen, Steven Spielberg e Jeffrey Katzenberg (FUNARI, 2012: 39), o livro de Chevitarese (primeiro de uma trilogia) tem por objetivo entender, "a partir da produção fílmica restrita às três primeiras décadas do século XX, como Jesus foi apropriado pelo cinema, especialmente no que se refere à sua estética, história e teologia" (CHEVITARESE, 2013: 15). 
relação entre cinema e antiguidade é quase tão antiga quanto a sétima arte", que desde a sua criação pelos irmãos Lumière, de forma direta ou indireta, tem recriado e representado personagens, temas e momentos das sociedades antigas. Foram os italianos, como lembra España (2013: 46), os primeiros a se especializarem, ainda no início do século XX, nas reconstruções históricas que retratavam, em especial, momentos da Roma Antiga, e que partiam de uma ideia nostálgica acerca de um suposto passado glorioso. Ao longo de toda a primeira metade do século XX, películas com enredos estabelecidos na antiguidade marcaram presença não apenas na indústria cinematográfica italiana, mas também no cinema norte-americano por meio dos épicos hollywoodianos, que tiveram nas produções do cineasta Cecil B. De Mille alguns de seus maiores representantes.

O grande boom dos filmes épicos voltados aos eventos e personagens da Antiguidade, porém, deu-se com o advento do subgênero peplum (do latim, por empréstimo ao grego antigo péplos, que pode ser traduzido como "túnica") produzidos durante as décadas de 1950 e 1960. Termo cunhado pelo crítico francês Jacques Sicilier (1962), peplum, ou como ficou conhecido no Brasil "histórias de espada e sandálias" (do inglês sword and sandal), refere-se aos filmes de cunho bíblico ou ambientados na antiguidade que adaptam para as telas, entre outros temas, o modo de vida romano, as histórias da mitologia e dos heróis gregos, a perseguição aos cristãos e as vidas dos governantes das cidades e impérios do mundo antigo. São produções que apresentam características semelhantes, como a presença de um governante sem 
escrúpulos, um herói que surge para libertar os oprimidos, a presença de uma mocinha que se apaixona pelo herói, e histórias que giram em torno de intrigas e disputas palacianas (ANTELA-BERNÁRDEZ, 2013: 158160). Atualmente, são considerados também como integrantes deste gênero os épicos produzidos por Hollywood, que por meio de representações da vida dos imperadores, dos cristãos, dos escravos, dos gladiadores e dos deuses, levaram um grande número de pessoas às salas dos cinemas para assistirem reconstruções monumentais de Roma. Arquétipos máximos dessas produções são, a título de exemplo, as películas "Quo Vadis” (1951) de Marvyn Leroy, "Ben Hur” (1959) de William Wyler, "Spartacus" (1960) de Stanley Kubrick, e "A queda do Império Romano" (1964) de Anthony Mann.

Após a década de 1970, a indústria cinematográfica assistiu a uma queda nas produções de "histórias de espada e sandálias", grande parte dos filmes épicos que retrataram Roma acabaram por tornarem-se fracassos de bilheteria, e como resultado, foram substituídos por produções que privilegiavam outras temáticas. Passaram-se mais de trinta anos até que, às vésperas do século XXI, o diretor inglês Ridley Scott desenterrou o gênero com o filme "Gladiador" (2000), sucesso de bilheteria que, ao abordar o Império Romano, representou-o à semelhança do Império Americano, com os seus jogos de poder, corrupções e decadências que estão presentes no imaginário contemporâneo a respeito dos EUA (BARROS, 2012: 75). Desde então, pode-se inferir que houve uma re-

\footnotetext{
${ }^{4}$ http://www.istoe.com.br/reportagens/350127_LUTAS+DESTRUICAO+E+SA I OTES. Acessado em 03/03/14.
} 
tomada pela mídia cinematográfica e televisiva de narrativas que representam momentos específicos da Antiguidade, tendo seu ápice na produção do seriado "Rome” (2005-2007), que tratar-se-á a partir de então ${ }^{5}$.

\section{O seriado "Rome": Usos do passado em narrativas do presente}

O seriado "Rome" (título em português - "Roma"), tendo como consultor de História Jonathan Stamp (mestre em Estudos Clássicos por Oxford e documentarista da BBC), foi criado por Bruno Heller, John Milius e William J. MacDonald, e produzido pelas redes de televisão HBO (Estados Unidos) e BBC (Inglaterra), em parceria com a RAI (Itália). As filmagens da série, composta por 22 episódios (12 em sua primeira temporada, e, 10 na segunda), foram realizadas na Cinecittà, Itália, estúdio famoso por ser associado aos grandes diretores italianos, como Fellini, e também por filmes épicos, sendo a película "Cleópatra"

\footnotetext{
${ }^{5}$ Outros exemplos atuais de produções classificadas como "histórias de espada e sandálias" que alcançaram sucesso de bilheteria e público são a série de TV "Spartacus" (2005-2007), produzida pela Starz, e as narrativas fílmicas lançadas no primeiro semestre de 2014: "300 - A ascensão do Império", de Noam Murro, "Pompeia" de Paul W.S. Anderson, e, "Hércules" de Renny Harlin. Ainda nos anos 2000 ganharam destaques os filmes "Troia" (2004), "300" (2006), "Fúria de Titãs" (2010), "Príncipe da Pérsia" (2010) e "Imortais" (2011). Para o crítico brasileiro Ivan Claudio (2014), o sucesso de tais narrativas demonstra que esse gênero de aventura histórica ganhou novos fãs e acrescenta que, "quando foi um fenômeno nos anos 1950 e 1960 e manteve a todo vapor a máquina do cinema italiano, as aventuras de "espada e sandálias", com seus déspotas e escravos rebelados, serviam de comentário à luta pelos direitos civis. Hoje, por sua vez, refletem o militarismo e a sucessiva queda de governos corruptos".
} 
(1963) de Rouben Mamoulian e Joseph L. Mankiewicz ${ }^{6}$ a mais conhecida. Considerada como uma das séries de televisão mais premiada $^{7} \mathrm{e}$ cara da história, com o custo de UU\$ 100 milhões por temporada (CYRINO, 2008; FEITOSA \& VICENTE, 2012), “Rome” foi transmitida originalmente entre 28 de agosto de 2005 e 25 de março de 2007. No Brasil, em canal aberto, foi ao ar pela primeira vez no dia 08 de janeiro de 2013 na Bandeirantes, rede de televisão conhecida popularmente como Band, onde foi exibida às terças-feiras no horário das $22 \mathrm{~h} 30^{8}$. O projeto original de "Rome", que previa cinco temporadas, sofreu modificações no início da segunda, quando a $\mathrm{HBO}$ e BBC optaram pelo cancelamento do seriado devido ao grande investimento que exigia a sua produção. Com a decisão de cancelamento das três últimas temporadas, os criadores se viram obrigados a encurtar as quatro temporadas que estavam planejadas dentro da segunda, deixando muita coisa de fora e

\footnotetext{
${ }^{6}$ Antes do início das gravações de "Roma" na Cinecittà, dois grandes filmes, sucesso de bilheteria, rodados nos estúdios foram "Gangues de Nova York" (2002) de Martin Scorsese, e "A paixão de Cristo" (2004) de Mel Gibson. O produtor executivo e roteirista de "Roma", Bruno Heller, em entrevista para os extras do DVD da primeira temporada, classifica Cinecittà, com os seus oito hectares, e, localizada nos arredores de Roma, como um dos melhores estúdios do mundo, que por seu tamanho, foi fundamental para montar os cenários da série.

${ }^{7}$ Roma venceu quatro das oito categorias do prêmio Emmy, em 2006, por sua primeira temporada. No ano seguinte, a segunda temporada da série levou três Emmys, de sete indicações. O Globo de Ouro, o BAFTA e o Satellite Awards também indicaram Roma em diversas categorias. Informações disponíveis em: http://www.boxdeseries.com.br/site/curiosidades-epicas-de-roma/. Acessado em 10/05/2014.

${ }^{8}$ Informações disponíveis em:

http://loucospelatv.blogspot.com.br/2013/01/serie-mais-cara-da-historiaroma.html. Acessado em 01/11/2013.
} 
impondo um ritmo apertado para terminar parte da história prevista no projeto original. Um dos enredos que teve que ser abandonado, por exemplo, foi a ascensão de Jesus Cristo, prevista para o que seria a quarta temporada?

O seriado americano-britânico teve como enredo o drama histórico da transição da antiga Roma republicana para a Roma imperial, mostrando as lutas pelo poder entre os principais generais da época. A série começa em 52 a.C, quando Júlio César derrota seu inimigo Vercingetórix na batalha de Alésia, e termina em 27 a.C, com a morte de Marco Antônio e Cleópatra, e a ascensão de Otávio Augusto como o primeiro imperador romano. Para ambientar esta troca histórica, a série se baseou não só nos poderosos que promoveram a transição, mas também nas vidas dos legionários Lucius Vorenus e Titus Pullo, personagens que aparecem no livro V da obra De bello galico ("Sobre a Guerra das Gálias”), escrito por César no período em que guerreara na Gália. Além das já citadas, o seriado apresenta outras personagens históricas, como Cícero, Catão (o Jovem), Brutus, Pompeu, Ptolomeu XIII, Potino, Teódoto de Quíos, Aquilas, Cesário, Calpúrnia, Otávia, Servília Caepionis, Átia dos Júlios, Cornélia, Lívia, e, uma série de personagens fictícios. Como escreve Monica Syrino (2008: 04), essa combinação de personagens reais e ficcionais não é algo excepcional, mas pode ser encontrada em praticamente todos os filmes baseados em histórias da Roma Antiga,

\footnotetext{
9 Informações disponíveis em: http://www.ambrosia.com.br/serie-roma-podeir-para-os-cinemas/. Acessado em 01/11/2013.
} 
desde Quo Vadis (1951) até “Gladiador” (2000), e é uma marca criativa da HBO em outros programas de televisão, como o aclamado drama americano Deadwood (2004-2006) de David Milch ${ }^{10}$.

Diferente de outros filmes e seriados produzidos acerca de eventos e personagens da Roma Antiga, em “Rome”, a cidade sede do império é representada de forma perversa, suja, degradada, com animais soltos pelas ruas, que remete a uma impressão de velhice. Segundo Daniel Acon, supervisor de efeitos especiais, isso foi colocado nas telas porque historicamente, Roma seria diferente da imagem que foi construída pelos pintores renascentistas, uma vez que era "suja, molhada e úmida por causa dos aquedutos, e havia muita ação entre incêndios, fumaça e canos vazando". Além disso, as construções no período em que se passa a série em sua maioria já possuía mais de duzentos anos, e, por isso, teriam formas envelhecidas. O produtor executivo e roteirista Bruno Heller, nas informações especiais contidas no DVD de "Rome" explicou que a proposta geral da série,

Não era de impressionar pelo espetáculo e por efeitos visuais, porque é muito fácil deixar tudo maravilhoso, incrível, grandioso e não lidar realmente com os personagens. (...) A ideia original era criar a cidade como ela era, cheia de pedras, encardida, suja e esfumaçada, o contrário do clichê cinematográfico de Roma, com suas muralhas de mármore, tudo limpo e majestoso.

10 "Such a combination of real and fictional characters can be found in virtually all films based on ancient Roman history, from Quo Vadis (1951) to Gladiator (2000), and it is also a creative hallmark of other historically themed television programs on $\mathrm{HBO}$, such as the acclaimed Western drama, Deadwood". (CYRINO, 2008: 04). Tradução livre realizada pelo autor. 
Percebe-se, por meio de suas falas, que o intuito dos produtores e roteiristas da série era de retratar Roma o mais perto possível da realidade, não deixando, nas palavras de Heller, que o seriado "soasse apenas como reprodução barata de sua época, parecendo fruto de colagens aleatórias de diversas épocas sob as quais se coloca uma camada de moralidade moderna." Tais afirmações, porém, permitem questionamentos acerca do quão ilusório é o pensamento dos produtores de "Rome", uma vez que filmes e programas de TV, como assinalam Feitosa e Vicente (2012: 182) são construções idealizadas por um ou mais indivíduos não como espelho da sociedade, e muito menos reprodução da História do modo como aconteceu, mas sim como uma interpretação e representação dela.

Não se pretende discutir se os eventos mostrados ao longo dos 22 episódios de "Roma" são verdadeiros ou fictícios, uma vez que, para compor a série, os roteiristas se utilizaram em grande parte de documentos e autores da Antiguidade, mas os leram a partir de óticas e perspectivas de seu tempo, sociedade e cultura. Portanto, não se espera encontrar na produção a realidade, mas apenas aparências de realidade (FUNARI, 2012: 25) que estão influenciadas por problemáticas do período histórico em que a série foi produzida. O que interessa neste momento é discutir algumas das influências do presente que aparecem em certas representações da cidade de Roma e da sociedade romana na produção; que, mesmo quando involuntárias por parte de seus criadores, a marcam como uma série produzida dentro de seu contexto histórico. Um exemplo interessante de influências do presente numa produção que diz ser de 
“fidelidade impressionante" (FEITOSA; VICENTE, 2012: 184), é como e em quê os produtores se basearam para montar a cidade de Roma. Bruno Heller que em outro momento defendeu produzir um trabalho que não soasse como produção da época, ao tratar da forma como o diretor de arte Joseph Bennett trabalhou com a construção da Roma cenográfica, explica que,

Ao contrário de pessoas que vieram com pesquisas históricas, Joe veio com as coisas bizarras: fotografias de Mary Ellen Frank, imagens de Mumbai, da Cidade do México e dos interiores da velha Havana; era claro que ele tinha habilidades técnicas rigorosas, mas também uma estética nova e imaginativa sobre como deveria ser, e queríamos que ficasse autêntico e preciso, mas também estranho e belo, e Joe captou isso imediatamente ${ }^{11}$.

Joseph Bennett, por sua vez, explica que escolheu ter essas cidades como modelo para a construção de Roma, porque muitas das interpretações que se tem da cidade são as obras produzidas pelos pintores clássicos dos séculos XVII e XVIII, e que neste caso, "são interpretações meio romantizadas"; e o que eles queriam, nas palavras de Bennett, era "tentar fazer algo mais honesto e fidedigno à vida" como é o caso das cidades indianas, assim como "algo vivo, pulsante, movimentado e que se tornasse uma personagem", como é o caso da cidade de Nova York, que "está sempre em movimento, com uma mistura de pessoas e carros indo e vindo a todo o momento, muito barulho, conversa, cansaço, fúria e certa pitada de diversão e esplendor" (idem).

${ }^{11}$ Informações retiradas dos extras do DVD da primeira temporada de "Roma", disponível no Disco 06. 
Ao assistir o seriado, logo se desprende da chamada "Roma Sagrada" que é a imagem que se tem em outros filmes e seriados, e depara-se com uma Roma parecida, em suas estruturas materiais, com as cidades indianas atuais e com a mesma movimentação da cidade de Nova York - há escravos, patrícios, plebeus e certa movimentação em todo o momento que as personagens caminham pelas ruas -, porém, é aí que está presente o cerne da questão acerca das influências de nosso tempo. O que se vê de longe é o que poderia ter sido a Roma do século I a.C, pois é impossível reconstituí-la da mesma forma que ela fora, fazendo com que sua construção seja um reflexo de nosso tempo; não se deve, nem se consegue afirmar que ela tenha tido características parecidas com as que Mumbai ou Nova York possuem, sem cometer um sério anacronismo. Utilizar cidades indianas como exemplo para construir a cidade cenográfica, é afirmar, de certa forma, que Mumbai, por exemplo, está num estágio de desenvolvimento que Roma passou há mais de dois mil anos, ou seja, Mumbai seria uma cidade subdesenvolvida quando comparada com outras cidades do presente. Ao passo que, Roma, como capital de um império teria possuído certas características semelhantes aos grandes centros políticos e econômicos atuais, como a cidade de Nova York. Seria mera coincidência as comparações entre Roma e Nova York? Com tais afirmações presentes nos discursos daqueles que produziram a série, torna-se difícil negar que "Rome” não tenha tido influências de nosso tempo ou que até mesmo não tenha sido feita uma nova criação do que teria sido a cidade de Roma, afetando a maneira como vemos o passado (ROSENSTONE, 2010: 18). 
Pode-se entender que para além de certas influências em relação à arquitetura e ideologias modernas, "Rome” também as teve, em certa medida, quanto à moda. Nos anos em que foi produzido, entre os países do chamado Ocidente, estava em alta a cultura indiana (os vestidos coloridos, os longos véus, as danças) ${ }^{12}$ como consequência, em especial, mas não apenas, do crescimento da Índia no mercado internacional; sua caracterização como membro do grupo $\operatorname{BRICS}^{13}$ e sua maior presença no cenário ocidental ${ }^{14}$; e, internacionalização dos filmes de Bollywood esforço esse que caracterizou o cinema indiano na primeira década do

${ }^{12}$ É válido lembrar que em menos de dois anos após a exibição do último capítulo de "Roma", foi ao ar no Brasil, em 19 de janeiro de 2009, pela Rede Globo de Televisão, o primeiro capítulo da novela "Caminho das índias", de Glória Pérez, que tratou, principalmente, de temas ligados à cultura indiana e seus marcos mais fortes e importantes, como o sistema de castas, o casamento arranjado, a longa preparação para um casamento, a questão dos intocáveis, entre outros. O que pode demonstrar, como a cultura do país asiático, uma das economias de mais rápido crescimento do mundo, estava se popularizando entre países da Europa e América, ao ponto de levar uma emissora brasileira a produzir uma telenovela sobre o tema. Também notório é o filme britânico "Quem quer ser um milionário" (2008) de Danny Boyle, adaptação do livro "Q \& A" do escritor indiano Vikas Swarup, indicado a dez Oscars e vencedor de oito, entre eles, o de melhor filme.

13 Para maiores informações acerca dos BRICS, acesse: http://www.itamaraty.gov.br/temas/mecanismos-inter-regionais/agrupamentobrics. Acessado em 17/05/2014.

${ }^{14}$ É importante destacar que esse não é o primeiro momento da História em que a Índia torna-se presente, de maneira influente, junto aos países do 'Ocidente'. É válido lembrar, por exemplo, as trocas culturais que passaram a existir entre ela e Grã-Bretanha a partir do momento em que tornou-se sua colônia - ainda no século XIX -, bem como as influências da filosofia de Mahatma Gandhi (1869-1948) no pensamento 'ocidental'. O que acredita-se que passa a ocorrer à partir dos anos 2000 é uma certa presença mais intensa da cultura indiana não apenas nos países europeus ou da América anglo-saxônica, mas também nos países latinos. 
século $\mathrm{XXI}^{15}$. O seriado, por sua vez, também foi levado por essa "nova onda Ocidental" ${ }^{\prime 16}$, de reconstruir alguns costumes e roupas daquele país cuja cultura, história e tradições, ainda no começo do século XXI, eram pouco conhecidas por parte de alguns dos moradores do Ocidente. Ao assistir “Rome”, não se tem a impressão de representações de ruas de uma cidade indiana apenas por sua estrutura física, mas também pelas roupas utilizadas pelas pessoas que nelas caminham, e, que nos remetem ao imaginário criado desse Oriente, uma vez que os tecidos utilizados na confecção das roupas das personagens femininas do seriado foram todos comprados na Índia pela figurinista April Ferry. Jonathan Stamp, consultor de História, também para os especiais do DVD da série, ao justificar as semelhanças entre o mundo romano e o indiano, perceptíveis em algumas cenas, explica que: "Ela [April Ferry] foi para a Índia, onde

${ }^{15}$ Apesar dessa internacionalização ocorrer apenas na primeira década do século XXI, o cinema indiano está dentre os mais antigos do mundo. Como explica em entrevista José Abílio Perez Júnior, doutorando em Ciências da Religião pela UFJF, as produções cinematográficas indianas começaram imediatamente após a chegada da nova invenção dos Lumiére, em finais de XIX, e, o primeiro longa-metragem indiano, de 1912, é anterior ao primeiro norte-americano, filmado em 1915 por D. W Griffith. Informações disponíveis em "Cinema indiano: passaporte para a realidade do povo da Índia": http://www.ihuonline.unisinos.br/index.php?option=com content $\&$ view $=$ article $\&$ id $=4837 \&$ secao $=412$. Acessado em 17/05/2014.

16 "Nova onda" porque há muito que o 'Ocidente' estabelece certos tipos de relações semelhantes, lida de forma parecida, com o 'Oriente', que em momentos distintos do passado, foi personificado por diferentes sociedades, como os persas, os egípcios, os chineses, os japoneses, entre outros. Relações essas que Edward Said (2007: 29) classifica como Orientalismo, um estilo de pensamento baseado numa distinção ontológica e epistemológica feita entre o 'Ocidente' e 'Oriente', "fazendo e corroborando afirmações a seu respeito, descrevendo-o, ensinando-o, colonizando-o, governando-o". 
comprou os tecidos e lá fez uma pesquisa, incorporando aquela cor vibrante ao visual [...] há mulheres de laranja, verde e azul por todo o cenário; e ficou tudo bem colorido, como era colorido o mundo romano".

Outra representação interessante é a presente na abertura da série, que traz pinturas parietais e grafites de Pompeia ao som da música composta e orquestrada por Jeff Beal, cuja melodia sugere certa inspiração advinda do ritmo musical indiano. Como apresentado em tópicos anteriores, mesmo que não seja o intuito de um roteirista ou diretor, a realização de uma ficção histórica se "justifica" de forma involuntária pela aproximação com o presente, e não pelo desejo de reconstruir fatos históricos (VIEGAS, 2001: 43). Com tais argumentos, não procura-se tirar a credibilidade do seriado como produto midiático, que possui um espetáculo visual belíssimo, roteiros inteligentes e atuações brilhantes (CYRINO, 2008: 03), mas sim, questionar o quanto e como conceitos e percepções modernas estão inseridos em produções cinematográficas e televisivas de época, tal como em produções historiográficas, em que nem mesmo os historiadores são capazes de contar os fatos da história tal como aconteceram (FEITOSA \& VICENTE, 2012: 182).

\section{Considerações finais}

O historiador Eric Hobsbawm (1998: 243), ao retomar algumas das ideias de Benedetto Croce e Robin Collingwood (1946: 293), argumentava que "toda História é História contemporânea disfarçada". Hobsbawm (1983: 01), ainda refletindo sobre as relações entre passado 
e presente na História, instiga-nos a pensar que as "tradições que parecem ou pretendem ser antigas são quase sempre de origem recente, e algumas vezes até inventadas". Ainda Hobsbawm (1983: 01), alhures, afirma que as tradições ditas antigas são na verdade inventadas para dar sentido a diversas práticas que "implicam automaticamente continuidade com o passado". Como destaca Guimarães (2008: 12), "automaticamente é um termo forte e 'continuidade' pode ser mais bem definida", uma vez que aquilo que é entendido como "continuidade" para Hobsbawm deveria ser melhor entendido como "invenção", "interpretação" ou “construção" (PINTO, 2011: 30) da História.

O cinema e a televisão, ao apresentarem sequências de fatos que acabam por reforçar determinadas cosmovisões (FEITOSA \& VICENTE, 2012: 179), assim como no caso de narrativas historiográficas, constroem determinados discursos, interpretações, construções, acerca do passado e presente. Independente das intenções dos produtores, narrativas midiáticas mostram o passado a partir de perspectivas do presente, visto que, por mais rigorosa que seja a recriação de cenários e vestuários, os personagens falarão e atuarão como o fazem na época em que o filme ou série é produzido, seguindo os usos, costumes e problemáticas daquele momento (ESPAÑA, 2013: 45). Análises voltadas às narrativas cinematográficas e televisivas que buscam retratar alguns momentos e personagens da Antiguidade permitem a construção de novos diálogos entre o estudioso desse período e a época no qual ele escreve (ANTELA-BERNÁRDEZ \& MARTÍN, 2013: 12). Tais diálogos propiciam, 
por sua vez, novas interpretações acerca das formas que o presente influi em representações do passado.

A renovação pelo interesse das chamadas "histórias de espada e sandálias" contribui para o surgimento de possíveis novos documentos aos estudiosos preocupados com a relação entre presente e passado por meio de produções midiáticas. Temas como gênero, sexualidade, imperialismo, política, raça, classe, entre outros, podem ser abordados a partir dos estudos de tais representações. Como inferiu Barros (2012: 7576), se os tempos recentes mostram a renovação de interesses por filmes ambientados na Antiguidade, "isso certamente diz algo ao historiador sobre o atual contexto sociocultural, ou mesmo político, que permitiu a renovação desse interesse".

Com tais pressupostos, ao longo do presente artigo procurou-se tratar de alguns dos discursos e narrativas criados a partir da produção do seriado "Rome". Longe de exaurir o tema, focou-se em um dos aspectos possíveis de análise da série. Outras possibilidades de estudo das representações da Roma do século I a. C que a produção busca realizar podem ser focadas, por exemplo, na construção de personagens históricas, na presença e forte participação feminina nos principais acontecimentos políticos (uma das marcas de "Roma"), na religiosidade por meio do culto aos deuses realizado pelas personagens, entre outros. Um estudo das representações de Júlio César e Cleópatra, por exemplo, bem como as oposições presentes entre as cidades de Roma e Alexandria, poderiam gerar amplos debates. Essas, porém, são questões que ficam para outros ensaios. 


\section{Referências Bibliográficas}

ANTELA-BERNÁRDEZ, B.; MARTÍN, C. S. (Org.). La Historia Antigua a través del cine - Arqueología, Historia Antigua y Tradición Clássica. Barcelona: Editorial UOC, 2013.

ANTELA-BERNÁRDEZ, B. "Nouvelle péplum? Nuevas corrientes en el cine sobre la Antigüedad". In ANTELA-BERNÁRDEZ, B.; MARTÍN, C. S. (Org.). La Historia Antigua a través del cine - Arqueología, Historia Antigua y Tradición Clássica. Barcelona: Editorial UOC, 2013, p. $155-164$.

BARROS, J. A. "Cinema e História: entre expressões e representações". In NÓVOA, J.; BARROS, J. D. (Org.). Cinema-História: teoria e representações sociais no cinema. $3^{\mathrm{a}} \mathrm{ed}$. Rio de Janeiro: Apicuri, 2012.

BURKE, P. A Escola dos Analles (1929-1989): a Revolução Francesa da Historiografia. Trad. Nilo Odalia. São Paulo: Fundação Editora da UNESP, 1997.

CAVICCHIOLI, Marina; FUNARI, Pedro P. A. "Os usos do passado: considerações sobre o papel da Arqueologia na construção da identidade nacional italiana". In VIERIA, Bruno V. G.; THAMOS, Márcio. Permanência Clássica: visões contemporâneas da Antiguidade grecoromana. São Paulo: Escrituras, 2011.

CERTEAU, Michel de. A escrita da História. Tradução de Maria de Lourdes Menezes. Rio de Janeiro: Forense, 2007.

CHARTIER, Roger. A História Cultural: entre práticas e representações. Rio de Janeiro: Bertrand, 1990.

CHEVITARESE, André L. Jesus no cinema: um balanço histórico e cinematográfico entre 1905-1927 (Volume 1). Rio de Janeiro: Editora Kline, 2013.

CLAUDIO, Ivan. Lutas, destruição e saiotes. ISTO É Independete, $\mathrm{n}^{\circ}$. 2310, 28 de fevereiro de 2014, atualizado em 11 de maio de 2014. 
COLLINGWOOD R. G. The Idea of History Oxford: Clarendon Press; Edição revisada com introdução de Jan Van der Dussen, Oxford: OUP, 1993.

CYRINO, Monica S. (Org.) Rome, season one: history makes television. Malden, MA: Blackwell Pub., 2008.

ESPAÑA, Rafael. "La Antiguedad al servicio de la actualidad. Cómo las ideas del presente influyen en la recreación cinematográfica del passado". In ANTELA-BERNÁRDEZ, B.; MARTíN, C. S. (Org.). La Historia Antigua a través del cine - Arqueología, Historia Antigua y Tradición Clássica. Barcelona: Editorial UOC, 2013.

FAZIO, A. H. P. Crítica à imagem eurocêntrica: uma reflexão acerca das representações étnicas e culturais em Hollywood. Anais do II Encontro Nacional de Estudos de Imagens. Londrina, maio de 2009.

FEITOSA, Lourdes M. G. C.; SILVA, Glaydson J. "O Mundo Antigo sob lentes contemporâneas". In FUNARI, Pedro Paulo A.; SILVA, Maria A. O. (Org.) Política e Identidades no Mundo Antigo. São Paulo: Annablume, 2009; p. 209-250.

FEITOSA, Lourdes M. G. C.; VICENTE, Maximiliano C. "Masculinidade do soldado romano: uma representação midiática". In CARVALHO, M. M.; FUNARI, P. P. A.; CARNAN, C. U.; SILVA, E. C. M. (Org.) História Militar do Mundo Antigo: Guerras e Representações. São Paulo: Annablume, 2012; p. 177-191.

FUNARI, Raquel S. O príncipe do Egito: um filme e suas leituras na sala de aula. São Paulo: Editora Annablume, 2012.

GARRAFFONI, Renata. S. Cultura material Greco-romana: algumas reflexões acerca do ensino e pesquisa de Arqueologia Clássica no Brasil. Romanitas - Revista de Estudos Grecolatinos, n. 2, p. 219-230, 2013. 
GUIMARÃES, J. O. "Reatualizar a Tradição Clássica". In CHEVITARESE, André L.; CORNELLO, Gabriele; SILVA, Maria A. O. A tradição Clássica e o Brasil. Brasília: Archai-UnB/Fortium, 2008; p. 11-13.

HOBSBAWM, E.; RANGER, T. The Invention of Tradition. Cambridge: CUP, 1983.

HOBSBAWM, Eric J. Sobre a história. Tradução de Cid Knipel Moreira. São Paulo: Cia das Letras, 1998; p.243.

JENKINS, K. A História Repensada. Trad. Mario Vilela. $4^{\mathrm{a}}$ ed. São Paulo: Contexto, 2013.

KORNIS, Monica A. Cinema, televisão e história. Rio de Janeiro: Zahar, 2008.

MUNSLOW, A. Deconstructing history. Londres, Routledge, 1997.

NAPOLITANO, Marcos. "A história depois do papel”. In: PINSKY, Carla B. (Org.) Fontes históricas. 2. Ed. São Paulo: Contexto, 2008.

NÓVOA, J. “Apologia da relação cinema-história”. In NÓVOA, J.; BARROS, J. D. (Org.). Cinema-História: teoria e representações sociais no cinema. $3^{\mathrm{a}}$ ed. Rio de Janeiro: Apicuri, 2012.

PINTO, Renato. Duas Rainhas, um Príncipe e um Eunuco: gênero, sexualidade e as ideologias do masculino e do feminino nos estudos sobre a Bretanha Romana. Campinas, São Paulo, 2011. (Tese de Doutoramento).

ROSENTONE, Robert A. A história nos filmes, os filmes na história. Trad. de Marcello Lino. São Paulo: Paz e Terra, 2010.

SAID, Edward. Orientalismo: o Oriente como invenção do Ocidente. Trad. Rosaura Eichenberg. São Paulo: Companhia das Letras, 2007.

SICLIER, J. L'Age du Péplum. Cahiers du cinema, 1962, n. 131, 28-38. 
Cadernos de Clio, Curitiba, n. ${ }^{\circ}$ 5, 2014

SILVA, G. J. História Antiga e usos do Passado: um estudo de apropriações da antiguidade sob o regime de Vichy. São Paulo: Annablume, 2007.

VIEGAS, Ana C. Gladiador: uma arena de imagens. Alceu, v. $01-\mathrm{n}^{\mathrm{o}}$ 02 - p. 42 a 47 - jan/jun de 2001.

WYKE, M. Projecting the past Ancient Rome: cinema and history. London: Routledge, 1997. 